\title{
Message of Editor-in-Chief
}

\section{Vinod Kumar Dixit*}

Department of Pharmaceutical Sciences, Dr. Harisingh Gour Vishwavidyalaya, Sagar-470003, Madhya Pradesh, INDIA.

E-mail:vkdixit2011@rediffmail.com

I am happy to present this issue of Indian Journal of Natural Products (IJNP) after a considerably long period of time. The unprecedented delay was primarily because of Covid-19 pandemic and the desire of the executive council members and other office bearers to project it on international platform and also because of the paucity of quality papers/article benefitting and addressing the current science of natural products. It is our endeavour to publish the journal through internationally reputed publisher and I hope the publication of this issue will gear up and facilitate the process. I am thankful to the committee constituted for this purpose which has matured the proposal. I extend invitation to members, readers, contributors and fellow scientists active in natural products and phytomedicines to submit their manuscripts to enhance the overall quality of the journal. Together with the erudite team of our editorial board, we will work passionately to take the IJNP to the next level.

With best wishes for a very happy and successful 2021. 